\title{
Role of Risk Factors in the Incidence of Multidrug-Resistant Tuberculosis
}

\author{
Alya Putri Khairani, ${ }^{1}$ Prayudi Santoso, ${ }^{2}$ Elsa Pudji Setiawati ${ }^{3}$ \\ ${ }^{1}$ Faculty of Medicine, Universitas Padjadjaran \\ ${ }^{2}$ Department of Internal Medicine, Faculty of Medicine Universitas Padjadjaran-Dr. Hasan Sadikin General \\ Hospital, Bandung \\ ${ }^{3}$ Department of Public Health Faculty of Medicine, Universitas Padjadjaran
}

\begin{tabular}{|c|c|}
\hline \multirow[t]{3}{*}{ Abstract } & $\begin{array}{l}\text { Objective: To determine the risk factors that played roles in the incidence } \\
\text { of multidrug-resistant tuberculosis (MDR-TB) in such patients. Multidrug- } \\
\text { Resistant Tuberculosis is a form of tuberculosis caused by Mycobacterium } \\
\text { tuberculosis that is resistant to at least isoniazid and rifampicin. }\end{array}$ \\
\hline & $\begin{array}{l}\text { Methods: This was a case control study to compare MDR-TB to non-MDR-TB } \\
\text { pulmonary tuberculosis outpatients in Dr. Hasan Sadikin General Hospital, } \\
\text { Bandung on August-September 2014. Fifty MDR-TB outpatients were } \\
\text { included as the cases and } 50 \text { non-MDR-TB outpatients as controls. Data was } \\
\text { collected by questionnaires and patient's registration forms. Bivariate and } \\
\text { multivariate analyses were performed using chi-square test and multiple } \\
\text { logistic regression test, with p<0.05 considered significant. }\end{array}$ \\
\hline & $\begin{array}{l}\text { Results: From bivariate analysis, number of previous tuberculosis treatments, } \\
\text { regularity of previous treatment, and burden of cost were significant risk } \\
\text { factors for developing MDR-TB }(p<0.05) \text {; while from multivariate analysis, } \\
\text { number of previous TB treatments was the only risk factor that played a } \\
\text { significant role in the incidence of MDR-TB (OR } 24.12895 \% \text { CI } 6.771-85,976) \text {. }\end{array}$ \\
\hline $\begin{array}{l}\text { Received: } \\
\text { January10, } 2017\end{array}$ & $\begin{array}{l}\text { Conclusions: Patients and medication factors are risk factors that play } \\
\text { roles in the incidence of MDR-TB. The significant risk factor is the number of } \\
\text { previous TB treatment. }\end{array}$ \\
\hline $\begin{array}{l}\text { Revised: } \\
\text { May 16, } 2017 \\
\text { Accepted: }\end{array}$ & $\begin{array}{l}\text { Keywords: Multidrug-resistant tuberculosis, resistance, risk factors, } \\
\text { tuberculosis }\end{array}$ \\
\hline August 24, 2017 & $\begin{array}{l}\text { pISSN: 2302-1381; eISSN: 2338-4506; http://doi.org/10.15850/ijihs.v5n2.991 } \\
\text { IJIHS. 2017;5(2):57-63 }\end{array}$ \\
\hline
\end{tabular}

\section{Introduction}

Global situation of tuberculosis (TB) is getting worse with increasing numbers of TB case year by year. Worldwide, the rate of TB incidence reduction remained at only $1.5 \%$ from 2014 to 2015 with a mortality rate of 100,000 cases at the end of 2015. Currently, Indonesia is in the second country with the highest burden of TB. ${ }^{1}$

Another problem occurs when TB patients develop drug resistance. Multidrug resistant tuberculosis or known as MDR-TB is defined as a Mycobacterium tuberculosis infection that

Correspondence:

Alya Putri Khairani, Faculty of Medicine, Universitas Padjadjaran

Jl. Raya Bandung-Sumedang KM 21 Jatinangor,

Indonesia

e-mail: alyakhairani95@gmail.com is resistant to at least two of the first line drug, i.e. isoniazid and rifampicin., ${ }^{2,3}$ Multidrugresistant tuberculosis patients will have to take a new type of drug that is less effective, more complex, and also more expensive than the old regiment. Hence, the World Health Organization (WHO) declares MDR-TB as a threat for global health due to its high burden, both in social and economic aspects. ${ }^{1}$

In 2015, there were 480,000 new cases of MDR-TB worldwide. From all TB cases identified in Indonesia, $2.8 \%$ of the cases are primary MDR-TB while $16 \%$ of the cases are secondary MDR-TB. These numbers increase globally every year. ${ }^{1}$

Mycobacterium tuberculosis resistance can be triggered by multiple factors, both from the bacteria and human host. ${ }^{4-6}$ Therefore, the aim of this study was to explore the risk factors that play roles in the incidence MDR- 
TB in the population of patients in Dr. Hasan Sadikin General Hospital, Bandung, which is the highest health referral center in West Java.

\section{Methods}

This was a case-control observative analytical study performed at the Respirology and Critical Respiratory Care Division of the Internal Medicine Department, Dr. Hasan Sadikin General Hospital during the period of August to September 2014. This study was approved by the Ethical Committee of Dr. Hasan Sadikin General Hospital Bandung. All TB patients who were on TB treatment during the study period were included in this study. Cases were collected from MDR-TB outpatients under Directly Observed Treatment, Short-courseplus (DOTS-plus) treatment in MDR-TB clinic while controls were taken from pulmonary TB outpatients under Direct Observed Treatment, Short-course (DOTS) treatment in DOTS clinic.

Based on the minimum sample requirement calculated by using Lemeshow formula, 100 samples (consisted of 50 cases and 50 controls) were recruited using the consecutive sampling method. The inclusion criteria for cases were patients who had been diagnosed as MDRTB patients based on drug susceptibility test (DST) and GeneXpert. Meanwhile, patients who were confirmed as pulmonary TB patients based on either microbiological examination, smear test, chest X-ray, or other clinical means of diagnosis by experts were included as controls. Subjects who refused to participate were excluded.

Data collected were number of previous TB treatments, regularity of previous treatment, cost burden, side effects, and communication, information, and education measures provided by health provider regarding TB, TB treatment, consequences from defaulting the treatment, and MDR-TB.

A self-administered questionnaire that had been tested for validity and reliability were used to collect data. Subjects' demography were collected from the patient registration form. Statistical analyses conducted included Chi-square test for bivariate analysis and multiple logistic regression for multivariate analysis.

\section{Results}

The demographic characteristics of the study subjects were described (Table 1). Multidrug- resistant tuberculosis patients were mostly men $(66 \%)$ in their productive age, i.e. 14 to 54 years old (44\%). Many MDR-TB patients were unemployed at the time of the study (50\%). The same situation was also seen in the control population $(38 \%)$. In addition, the MDR-TB (64\%) patients and their controls (70\%) also did not have daily nor monthly income. Most MDR-TB patients used the national insurance (BPJS) to pay their treatment expenses (84\%). A great proportion of the MDR-TB patients had their first TB treatment at the primary health care (puskesmas) setting (60\%).

The risk factors studied were factors that significantly correlated with the incidence of MDR-TB, including number of previous TB treatments $(p=0.000)$, regularity of TB treatment $(p=0.001)$, and also burden of cost $(\mathrm{p}=0.003)$.

Multiple logistic regression was applied in the study (Table 3). The p value for these factors was considered significant if $\mathrm{p}<0.05$. Final regression showed that the only factor that played a significant role in the incidence of MDR-TB was the number of the previous TB treatments with and odd ratio (OR) of 24.128 (confidence interval 95\%, 6.771-85.976).

\section{Discussion}

Most of the MDR-TB patients in this study are men in productive age (Table 1). This is similar to the result of a study by Law et al. ${ }^{8}$ stating that many MDR-TB cases occur in patients with an average age of 48 years old. The same employment situation is also found for MDR-TB patients in this study and also in the study by Law et al. ${ }^{8}$ in which most patients are unemployed. The MDR-TB treatment which must be implemented daily at the hospital is the cause this situation.

Results in this study show that most MDRTB patients had experienced $>2$ previous TB treatments (Table 2). Such a high number is also found in various studies, ${ }^{6,8}$ From the perspective of the regularity of the previous treatment(s), it is revealed that there are 27 MDR-TB patients did not regularly consume the TB drugs during their previous treatment. The difference between the number of MDR-TB patients with regularl and irregular treatment is 4 patients with more patients performed irregular treatment. This slight difference can also be seen in a study concucted by Sarwani $e t$ $a l .{ }^{9}$ For burden of cost, the majority of MDR-TB patients felt that cost becomes a burden, with the ratio of 16:9. Similar numbers can also 
Table 1 Characteristics of MDR-TB Patients and Their Controls

\begin{tabular}{|c|c|c|c|c|}
\hline \multirow[b]{2}{*}{ Characteristics } & \multicolumn{4}{|c|}{ Categories } \\
\hline & $\begin{array}{c}\text { MDR-TB } \\
(n=50)\end{array}$ & $\%$ & $\begin{array}{c}\text { Non-MDR-TB } \\
(n=50)\end{array}$ & (\%) \\
\hline \multicolumn{5}{|l|}{ Sex } \\
\hline Men & 33 & 66 & 28 & 56 \\
\hline Women & 17 & 34 & 22 & 44 \\
\hline \multicolumn{5}{|l|}{ Age (yrs.) } \\
\hline $14-54$ & 44 & 88 & 41 & 82 \\
\hline$\geq 55$ & 6 & 12 & 9 & 18 \\
\hline \multicolumn{5}{|l|}{ Occupation } \\
\hline Civil servant & 0 & 0 & 2 & 4 \\
\hline Private employee & 2 & 4 & 4 & 8 \\
\hline Enterpreneur & 11 & 22 & 8 & 16 \\
\hline Housewife & 7 & 14 & 7 & 14 \\
\hline Labor/Farmer & 3 & 6 & 0 & 0 \\
\hline Student & 0 & 0 & 9 & 18 \\
\hline Unemployed & 25 & 50 & 19 & 38 \\
\hline \multicolumn{5}{|l|}{ Income per month } \\
\hline$<$ IDR 500,000 & 3 & 6 & 1 & 2 \\
\hline IDR $500,000-1,000.000$ & 10 & 20 & 7 & 14 \\
\hline >IDR $1,000.000$ & 5 & 10 & 7 & 14 \\
\hline None & 32 & 64 & 35 & 70 \\
\hline \multicolumn{5}{|l|}{ Healthcare payment } \\
\hline National insurance (BPJS) & 42 & 84 & 32 & 64 \\
\hline Insurance from workplace & 0 & 0 & 4 & 4 \\
\hline Personal/Family & 4 & 8 & 12 & 24 \\
\hline Other party & 0 & 0 & 2 & 4 \\
\hline Others & 4 & 8 & 2 & 4 \\
\hline \multicolumn{5}{|l|}{ Place to Receive First TB treatment } \\
\hline Primary Healthcare (puskesmas) & 30 & 60 & 2 & 4 \\
\hline Center for Lung Disease Treatment (BP4) & 2 & 4 & 0 & 0 \\
\hline Dr. Hasan Sadikin General Hospital & 2 & 4 & 42 & 84 \\
\hline Other Government General Hospital & 10 & 20 & 3 & 6 \\
\hline Private Hospital & 2 & 4 & 2 & 4 \\
\hline Private Practice Doctor & 4 & 8 & 1 & 2 \\
\hline
\end{tabular}

Note: $y r s .=$ years; IDR= Indonesian rupiahs 
Table 2 Risk Factors that Played Roles in the Occurrence of MDR-TB in MDR-TB Patients

\begin{tabular}{|c|c|c|c|}
\hline Factors & MDR-TB n (\%) & $\begin{array}{c}\text { Non-MDR-TB } \\
\text { n (\%) }\end{array}$ & p Value \\
\hline \multicolumn{4}{|c|}{ Number of previous TB treatment } \\
\hline 1 & $8(16)$ & $42(84)$ & \multirow{2}{*}{0.000} \\
\hline$\geq 2$ & $42(84)$ & $8(16)$ & \\
\hline \multicolumn{4}{|c|}{ Regularity of previous treatment } \\
\hline Regular & $23(46)$ & $39(78)$ & \multirow{2}{*}{0.001} \\
\hline Irregular & $27(54)$ & $11(22)$ & \\
\hline \multicolumn{4}{|l|}{ Burden of cost } \\
\hline Yes & $32(64)$ & $17(34)$ & \multirow{2}{*}{0.003} \\
\hline No & $18(36)$ & $33(66)$ & \\
\hline \multicolumn{4}{|l|}{ Side effects } \\
\hline Yes & $32(64)$ & $23(46)$ & \multirow{2}{*}{0.070} \\
\hline No & $18(36)$ & $27(54)$ & \\
\hline \multicolumn{4}{|c|}{$\begin{array}{l}\text { Communication, information, education } \\
\text { given by health officers }\end{array}$} \\
\hline Completely given & $20(40)$ & $27(54)$ & \multirow{2}{*}{0.161} \\
\hline Incompletely given & $30(60)$ & $23(46)$ & \\
\hline
\end{tabular}

be found for the side effects. This situation explained that factors related to the patients, i.e. regularity of previous treatment, burden of cost, and side effects) would provide sufficient differences in the high frequency distribution of the MDR-TB patients. ${ }^{10}$ Results from the questionnaires showed that some MDR-TB patients claimed that they had not received complete information on TB and MDR-TB. The complete information should include information on TB, TBtreatment, consequences related to defaulting TB treatment, and MDRTB. The health providers tend to forget to give information about MDR-TB. Nofizar et al. ${ }^{6}$ showed the same finding. Health providers do explain about MDR-TB with $98 \%$ of MDRTB patients in Persahabatan General Hospital, where the study was conducted, agreed to the statement.

The risk factors that played roles in the incidence of MDR-TB in MDR-TB patients are described (Table 2). Previous TB treatment is a strong factor that plays a role in the incidence of MDR-TB. A study in Belarus has revealed that the risk of MDR-TB to occur in TB patients increased 6.1 times if the patients were under TB treatments before MDR-TB. ${ }^{11}$
In Uganda, a study revealed that relapsed TB cases and failed TB treatment are associated with the occurrence of MDR-TB. ${ }^{12}$ Thus, it is possible that the number of TB treatment and the regularity of previous treatment affect the occurrence of MDR-TB.

To study about the relationship between the number of previous TB treatments before MDR-TB and the incidence of MDR-TB, it is important to understand the quality of the TB treatment first. Good quality treatment shows an adequate treatment. An inadequate treatment provides more opportunities for the accumulation of individual mutations. ${ }^{13}$ The treatment will not be able to eradicate the mutated bacteria. This circumstance will make the TB patients receive more than one treatment. Eventually, resistance develops and MDR-TB occur.

The regularity of TB treatment has a causal relationship with the occurrence of MDRTB. Irregular treatment, meaning that there are occasions where patients do not take the TB drugs as instructed, could increase the risk of relapse and eventually cause MDRTB. ${ }^{1,3,4}$ A study by Barroso et al. ${ }^{13}$ shows that irregularly treated patients has 7 times higher 
Table 3 Multiple Linear Regression Analysis and Estimation of Odds Ratio (OR) for the Risk Factors that Played Significant Roles to the Incidence of MDR-TB

\begin{tabular}{|c|c|c|c|c|}
\hline Variables & coef B & SE(B) & p value & Adj OR (CI 95\%) \\
\hline \multicolumn{5}{|l|}{ Initial regression model } \\
\hline $\begin{array}{l}\text { Number of previous } \mathrm{TB} \\
\text { treatment }\end{array}$ & 3.183 & 0.648 & 0.000 & $24.128(6.771-85.976)$ \\
\hline $\begin{array}{l}\text { Regularity of previous } \\
\text { treatment }\end{array}$ & -0.102 & 0.659 & 0.877 & $0.903(0.248-3.287)$ \\
\hline Burden of cost & 0.509 & 0.564 & 0.367 & $1.663(0.551-5.023)$ \\
\hline Side effects & 0.260 & 0.567 & 0.646 & $1.297(0.427-3.940)$ \\
\hline $\begin{array}{l}\text { Communication, information, } \\
\text { education given by health } \\
\text { officers }\end{array}$ & 0.548 & 0.629 & 0.327 & $1.729(0.579-5.168)$ \\
\hline \multicolumn{5}{|l|}{ Final regression model } \\
\hline $\begin{array}{l}\text { Number of previous TB } \\
\text { treatment }\end{array}$ & 3.183 & 0.648 & 0.000 & $24.128(6.771-85.976)$ \\
\hline
\end{tabular}

risk to develop MDR-TB when compared to the regularly treated patients. ${ }^{13}$ Another study also shows the same conclusion. ${ }^{9}$ Results from the questionnaires in the present study shows variety of circumstances known to be the reason for patients to take the treatment irregularly, and even cause the patients to not completely follow the scheduled treatment. Those circumstances are (1) patients are busy with their daily activities that they forget to take their medicine, (2) patients feel better making them only take the medicine once in a while, (3) patients do not have money during the treatment. Same situations are found in a study by Jaggarajamma et al. ${ }^{14}$

It follows that the number of previous $\mathrm{TB}$ treatments and the regularity of previous treatments are interrelated. ${ }^{13,15}$ An adequate TB treatment is defined as a treatment that follows the established rules, including the rule to take the medicine regularly. If the drugs are consumed irregularly, the treatment will be inadequate, hence it becomes a poor quality treatment. In the end, this may affect the number of TB treatments received and may lead to the occurence of MDR-TB $\cdot{ }^{13}$ Similar pattern can be seen in this study.

Burden of cost during TB treatment affects the incidence of MDR-TB. The costs that are incurred during treatment is also taken into considerations when TB patients considering whether to continue the treatment during the course of treatment. Many patients decided to stop treatment due to the burden of cost. Hill et $a l .{ }^{16}$ found the same situation in Gambia. There are many situations related tothe burden of cost during treatment that causes patients to default from treatment and contributes to the occurrence of MDR-TB. According to Wahab et $a .^{17}$ one of the situations is the drug financing that is applied when TB treatment is obtained outside the DOTS program. However, this study found another situation. According to the MDR-TB patients, the burdens that they felt as the most difficult is the lost of working time and being unemployed during the treatment. Patients who are enterpreneurs and labors admitted that TB, MDR-TB, and their treatment disturb their work during the day and make them delay their work, especially during the intensive months of treatment (1-2 months). In the meantime, patients do not receive daily nor monthly income as usual. Those situations make the financial burden more difficult to bear. ${ }^{16}$ Furthermore, due to the long period of TB treatment, transportation cost also becomes a heavy burden to the patients. Those problems are felt by both MDR-TB patients and their control.

Result of this study shows that the side effects of the treatment do not play roles in the incidence of MDR-TB. This statement is supported by the fact that both groups are complaining about side effects during TB treatment. Although the side effects are disturbing, some patients are not bothered 
by the effects and can continue the treatment without any obstacle. As a result, this study cannot prove the causal relationship between side effects and the incidence of MDR-TB. A previous study stated otherwise by stating that the side effects is a strong factor that influences the incidence of MDR-TB. ${ }^{10}$ Communication, information, and education given by the health provider do not have any causal relation with the occurrence of MDR-TB. The result of the questionnaires have shown that some MDRTB patients and their controls did not receive information about MDR-TB and only received information regarding $\mathrm{TB}$, its treatment, and the consequences from defaulting the TB treatment, which is incomplete. On the contrary, despite those problems, there are patients who still adhere well to the treatment. This situation shows that this incomplete communication, information, and education may lead to disappointment among patients and still reminds the patients to adhere with treatment. However, Nofizar et al. ${ }^{6}$ found the contrary with ninety percents of MDR-TB patients stated that the health provider did not communicate, educate, and give information regarding MDR-TB and they did not follow the treatment thoroughly.

The results from the multivariate analysis show that of all possible risk factors that may influence the incidence of MDR-TB, the number of previous TB treatments is the only risk factor with is significant statistically (Table 3 ). Patients with $\geq 2$ previous TB treatments have a 24 times higher risk to obtain MDR-TB. This statement is also supported by studies by Barroso et al. ${ }^{13}$ and Zhao et al. ${ }^{7}$ in which patients who had received multiple treatments for tuberculosis are 13 times as likely to have MDR tuberculosis compared to those who had received only one prior treatment.

Despite the fact that the number of previous TB treatments is strongly correlated with the regularity of previous treatment, multivariate analysis shows that the regularity of previous treatment is not a risk factor that plays a significant role in the incidence of MDR-TB. This result is also found in a study by Garcia Vázquez et al. ${ }^{18}$ If the MDR-TB patients had TB treatment(s) before the occurrence of MDRTB, the patients will have at least a minimum risk to develop MDR-TB, even though the previous treatment was adequate. ${ }^{13,18}$ This situation can be explained as follow. In the first month of $\mathrm{TB}$, patients might receive mutated Mycobacterium and become resistant to the treatment even before the treatment is started. ${ }^{7}$ This situation is called primary MDR-TB. The signs and symptoms of MDR-TB are not different from TB, making it common that patients with primary MDR-TB receive the usual first line TB treatment. In fact, any drug for susceptible-TB will not be effective to eliminate resistant Mycobacterium. The MDR-TB patients are likely to continue with the TB treatment, then move to the second line, until a screening for MDR-TB suspects is conducted. ${ }^{19,20}$ Nevertheless, Garcia Vázquez et al ${ }^{18}$ stated that the risk of MDR-TB to occur by the factor of the number of previous TB treatments alone is minimum.

Burden of cost is not one of the risk factors that play a significant role to the occurrence of MDR-TB. This study shows that most MDR-TB patients received previous TB treatment at the primary health center. Some of these patients stated that they went to the primary health center on foot. In primary health center, the TB treatment program is paid by the government, thus provided free of charge. This makes things easier for the patients. Although patients may have financial problems in other aspects, they can still go to the primary health center to receive treatment.

The major limitations of this study is that the cases and controls were not 'matched' beforehand. In this study, the calculation of pharmacokinetic drug levels in the two groups of the samples are also not considered. In addition, comorbids are not taken into account.

In conclusions, the risk factors to develop MDR-TB can come from patients themselves, including the regularity of the treatment and burden of cost, and can also be generated from the drug factor, which is the number of previous TB treatments. Of these, the number of previous TB treatments plays an important role in the incidence of MDR-TB.

\section{References}

1. WHO. Global Tuberculosis Report 2016. Geneva, Switzerland: WHO; 2016.

2. Nathanson E, Nunn P, Uplekar M, Floyd $\mathrm{K}$, Jaramillo E, Lönnroth $\mathrm{K}$, et al. MDR

tuberculosis-critical steps for prevention and control. N Eng J Med. 2010;363(11):1050-8.

3. Gandhi NR, Nunn P, Dheda K, Schaaf HS, Zignol $\mathrm{M}$, Soolingen DV, et al. Multidrug-resistant 
and extensively drug-resistant tuberculosis: a threat to global control of tuberculosis. Lancet. 2010;375(9728):1830-43.

4. Chiang CY, Centis R, Migliori GB. Drug-resistant tuberculosis: past, present, future. Respirology. 2010;15(3):413-32.

5. Fauci AS. Multidrug-resistant and extensively drug-resistant tuberculosis: the national institute of allergy and infectious diseases research agenda and recommendations for priority research. J Infect Dis. 2008;197(11):1493-8.

6. Nofizar D, Nawas A, Burhan E. Identification of risk factors in multidrug resistant tuberculosis. MJI. 2011;60(12):537-45.

7. Zhao $\mathrm{Y}, \mathrm{Xu} \mathrm{S}$, Wang L, Chin DP, Wang S, Jiang $\mathrm{G}$, et al. National survey of drugresistant tuberculosis in China. $\mathrm{N}$ Engl J Med. 2012;366(23):2161-70.

8. Law WS, Yew WW, Chiu Leung C, Kam KM, Tam $\mathrm{CM}$, Chan $\mathrm{CK}$, et al. Risk factors for multidrugresistant tuberculosis in Hong Kong. Int J Tuberc Lung Dis. 2008;12(9):1065-70.

9. Sarwani D, Nurlaela S, Isnani ZA. Analisis faktor risiko multidrug resistant tuberculosis (MDRTB) (Studi Kasus di BP4 Purwokerto). JKM. 2013;8(1):62-8.

10. Caminero JA. Multidrug-resistant tuberculosis: epidemiology, risk factorsand case finding [State of the art series. Drug-resistant tuberculosis. Int J Tuberc Lung Dis. 2010;14(4):382-90.

11. WHO. Multidrug-resistant tuberculosis in Belarus: the size of the problem and associated risk factors. Bull WHO. 2013;91(1):36-45.

12. TempleB,AyakakaI, Ogwang S,Nabanjja H,Kayes S, Nakubulwa $\mathrm{S}$, et al. Rate and amplification of drug resistance among previously-treated patients with tuberculosis in Kampala, Uganda. Clin Infect Dis. 2008;47(9):1126-34.

13. Barroso EC, Mota RMS, Santos RO, Sousa ALO, Barroso JB, Rodrigues JLN. Risk factors for acquired multidrug-resistant tuberculosis. J Pneumologia. 2003;29(2):89-97.
14. Jaggarajamma K, Sudha G, Chandrasekaran V, Nirupa C, Thomas A, Santha T, et al. Reasons for non-compliance among patients treated under Revised National Tuberculosis Control Programme (RNTCP), Tiruvallur district, South India. Indian J Tuberc. 2007;54(3):130-5.

15. Lomtadze N, Aspindzelashvili R, Janjgava M, Mirtskhulava V, Wright A, Blumberg HM, et al. Prevalence and risk factors for multidrugresistant tuberculosis in the Republic of Georgia: a population-based study. Int J Tuberc Lung Dis. 2009;13(1):68-73.

16. Hill PC, Stevens W, Hill S, Bah J, Donkor SA, Jallow A, et al. Risk factors for defaulting from tuberculosis treatment: a prospective cohort study of 301 cases in the Gambia. Int J Tuberc Lung Dis. 2005;9(12):1349-54.

17. Wahab F, Ashraf S, Khan N, Anwar R, Afridi MZ. Risk factors for multi-drug resistant tuberculosis in patients at tertiary care hospital, Peshawar. J College Physicians Surg Pakist. 2009;19(3):162-4.

18. García Vázquez E, Esteban J, De Gorgolas M, Fernández Guerrero ML. Infection by resistant Mycobacterium tuberculosis in a hospital population. A longitudinal study of incidental cases at the Fundacion Jimenez Diaz. Revista Clinica Espanola. 1999;199(9):564-8.

19. Otero L, Krapp F, Tomatis C, Zamudio C, Matthys F, Gotuzzo E, et al. High prevalence of primary multidrug resistant tuberculosis in persons with no known risk factors. PLOS ONE [serial on the internet]. 2011 Oct [cited 2014 Aug 12];6(10):[about 7p.]. Available from: http://journals.plos.org/plosone/ article?id=10.1371/journal.pone.0026276.

20. Turbawaty DK, Gustiani N, Noviani L, Parwati I. Validity of Mycobacterium tuberculosis Antigens Cocktail: ESAT-6, CFP-10 and MPT64 in Sputum and Cerebrospinal Fluid for Pulmonary Tuberculosis and Tuberculous Meningitis Diagnosis. IJIHS. 2015;3(2):60-5. 